\title{
Incidence of severe pain in newly diagnosed ambulatory patients with stage IV cancer
}

\author{
Thomas Isaac MD MBA MPH ${ }^{1,2}$, Sherri O Stuver $\mathrm{ScD}^{1,3}$, Roger B Davis $\mathrm{ScD}^{2}$, Susan Block $\mathrm{MD}^{4}$, \\ Jane C Weeks MD MSc ${ }^{5}$, Donna L Berry RN PhD ${ }^{6}$, Saul N Weingart MD PhD ${ }^{1}$
}

T Isaac, SO Stuver, RB Davis, et al. Incidence of severe pain in newly diagnosed ambulatory patients with stage IV cancer. Pain Res Manage 2012;17(5):347-352.

BACKGROUND: Pain is common among cancer patients. OBJECTIVE: To characterize the incidence of severe pain among newly diagnosed patients with stage IV cancer in ambulatory care.

METHODS: A retrospective cohort of 505 ambulatory oncology patients with newly diagnosed stage IV solid tumours at a comprehensive cancer centre (Dana-Farber Cancer Institute, Boston, Massachusetts, USA) was followed from January 1, 2004, to December 31, 2006. Pain intensity scores were extracted from electronic medical records. The incidence of severe pain was calculated using the maximum monthly pain scores reported at outpatient visits.

RESULTS: Of the 505 patients included in the present study, 340 (67.3\%) were pain-free at the initial visit, $90(17.8 \%)$ experienced mild pain, $48(9.5 \%)$ experienced moderate pain and 27 (5.4\%) experienced severe pain. At least one episode of severe pain within one year of diagnosis was reported by $29.1 \%$ of patients. Patients with head and neck, gastrointestinal and thoracic malignancies were more likely to experience severe pain compared with patients with other types of cancer $(52.6 \%, 33.9 \%$ and $30.5 \%$, respectively). In the multivariable model, patients whose primary language was not English (OR 2.90 [95\% CI 1.08 to 7.80]), patients who reported severe pain at the initial visit (OR 9.30 [95\% CI 3.72 to 23.23]) and patients with head and neck (OR 10.17 [95\% CI 2.87 to 36.00]) or gastrointestinal (OR 4.05 [95\% CI 1.23 to 13.35]) cancers were more likely to report severe pain in the following year.

CONCLUSIONS: The incidence of severe pain was high in ambulatory patients with newly diagnosed stage IV cancer.

Key Words: Cancer; Electronic health record; Epidemiology; Incidence; Pain intensity; Palliative care; Risk factors

A growing body of research suggests that patients with advanced cancer are at a high risk of experiencing severe pain (1-7). The authors of a 2007 systematic review (3) reported a pain prevalence of $64 \%$ among patients with advanced, metastatic or terminal cancer. Other studies have reported a pain prevalence of $30 \%$ to $60 \%$ in cancer patients, although frequencies as low as $14 \%$ and as high as $100 \%$ have also been described (3-7). Severe pain is debilitating and undermines quality of life, causes functional impairment and affects the ability to perform activities of daily living.

Despite the increasing knowledge of patterns of cancer pain, including breakthrough pain (8-10), few studies have examined the incidence of pain during routine ambulatory cancer treatment and follow-up (4-6,11). The incidence of pain among ambulatory patients with various types of stage IV cancer is not well characterized. Therefore, this particularly vulnerable and understudied group was the target of the present study. The ability to extract and analyze information regarding these patients' pain intensity from medical

\section{L'incidence de douleur sévère chez les patients ambulatoires atteints d'un cancer de phase IV nouvellement diagnostiqués}

HISTORIQUE : La douleur est courante chez les patients cancéreux. OBJECTIF : Caractériser l'incidence de douleur sévère chez les patients en soins ambulatoires atteints d'un cancer de phase IV nouvellement diagnostiqués.

MÉTHODOLOGIE : Les chercheurs ont suivi une cohorte rétrospective de 505 patients en oncologie ambulatoire ayant des tumeurs solides de phase IV nouvellement diagnostiquées qui fréquentaient un centre de soins complets du cancer (le Dana-Farber Cancer Institute de Boston, au Massachusetts,

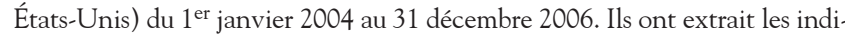
ces d'intensité de la douleur des dossiers médicaux électroniques. Ils ont calculé l'incidence de douleur sévère au moyen des indices de douleur mensuelle maximale déclarés lors des visites en consultations externes.

RÉSULTATS : Sur les 505 patients inclus dans la présente étude, $340(67,3 \%)$ ne ressentaient pas de douleur lors de leur visite initiale, $90(17,8 \%)$ ressentaient une douleur légère, 48 (9,5\%), une douleur modérée et $27(5,4 \%)$, une douleur sévère. Dans l'année suivant le diagnostic, 29,1\% des patients ont déclaré au moins un épisode de douleur sévère. Les patients ayant des tumeurs malignes de la tête et du cou, du système gastrointestinal ou du système pulmonaire étaient plus susceptibles de ressentir des douleurs sévères que ceux ayant d'autres types de cancer $(52,6 \%, 33,9 \%$ et $30,5 \%$, respectivement). Dans le modèle multivariable, les patients dont la langue maternelle n'était pas l'anglais (RRR 2,90 [95 \% IC 1,08 à 7,80]), les patients qui avaient déclaré une douleur sévère à la première visite (RRR 9,30 [95 \% IC 3,72 à 23,23]) et ceux ayant un cancer de la tête et du cou (RRR 10,17 [95 \% IC 2,87 à 36,00]) ou du système gastro-intestinal (RRR 4,05 [95 \% IC 1,23 à 13,35]) étaient plus susceptibles de déclarer une douleur sévère au cours de l'année suivante.

CONCLUSIONS : L'incidence de douleur sévère était élevée chez les patients ambulatoires ayant un cancer de phase IV nouvellement diagnostiqué.

records would provide a mechanism for investigating the epidemiology of pain in individual practice settings, site-specific risk factors and local care patterns. This information could provide patients with advanced cancer and their clinicians with potentially useful information regarding what to expect during an illness, and could lead to practice-based improvement initiatives. Therefore, we sought to use existing clinical information captured in patients' electronic medical records to address a question that patients may ask their doctors: 'What is the chance that I will experience severe pain in the next year?'

\section{Study site}

\section{METHODS}

The present study included patients treated at the Dana-Farber Cancer Institute (DFCI), a National Cancer Institute-designated comprehensive cancer centre in Boston, Massachusetts. Clinical services include disease-focused programs in hematological and solid tumour

${ }^{1}$ Center for Patient Safety, Dana-Farber Cancer Institute; ${ }^{2}$ Division of General Medicine and Primary Care, Beth Israel Deaconess Medical

Center; ${ }^{3}$ Department of Epidemiology, Boston University School of Public Health; ${ }^{4}$ Department of Psychosocial Oncology and Palliative Care;

${ }^{5}$ Center for Outcomes and Policy Research; ${ }^{6}$ Phyllis F Cantor Center for Research in Nursing and Patient Care Services, Dana-Farber Cancer

Institute, Boston, Massachusetts, USA

Correspondence: Dr Saul N Weingart, Center for Patient Safety, Dana-Farber Cancer Institute, 450 Brookline Avenue, Boston, Massachusetts

02215, USA. Telephone 617-632-4935,fax 617-582-8070, e-mail saul_weingart@dfci.harvard.edu 


\section{TABLE 1}

\section{ICD-0-9 code classifications for malignancies}

\begin{tabular}{ll}
\hline Organ system & ICD codes \\
\hline Breast & C50.0-C50.9, except 9590-9989 \\
Thoracic & C34.0-C34.9, except 9590-9989 \\
Gastrointestinal & \\
Esophagus & C15.0-C15.9, except 9590-9989 \\
Liver and intrahepatic bile ducts & C22.0, C22.1, except 9590-9989; \\
Colon/rectum & C18.0-C18.9, C19.9, C20.9, C26.0 \\
& except 9590-9989 \\
Pancreas & C25.0-C25.9, except 9590-9989 \\
Stomach & C16.0-C16.9, except 9590-9989 \\
Urogenital & \\
Cervix uteri & C53.0-C53.9, except 9590-9989 \\
Corpus uteri and uterus & C54.0-C54.9, C55.9, except 9590-9989 \\
Kidney and renal pelvis & C64.9, C65.9, except 9590-9989 \\
Ovary & C56.9, except 9590-9989 \\
Prostate & C61.9, except 9590-9989 \\
Testis & C62.0-C62.9, except 9590-9989 \\
Urinary bladder (includes in situ) & C67.0-C67.9, except 9590-9989 \\
Head and neck & \\
Oral cavity and pharynx & C00.0-C14.8, except 9590-9989 \\
Thyroid & C73.9, except 9590-9989 \\
Larynx & C32.0-C32.9, except 9590-9989 \\
Other & \\
Brain and other nervous system & C70.0-C72.9, except 9590-9989 \\
Melanoma of skin & C44.0-C44.9 (includes 8720-8790) \\
Sarcoma & C40.0-C41.9 \\
\hline Adapted fra Cancer Ince &
\end{tabular}

Adapted from Cancer Incidence and Mortality in Massachusetts 2002-2006: Statewide Report (13). ICD International Classification of Disease

malignancies and extensive research programs. The DFCI treats patients from metropolitan Boston as well as patients in a regional and national referral network. The centre employs more than 150 physicians and 200 nurses.

\section{Data resources}

Pain intensity scores were extracted from electronic medical records for all patient visits at the DFCI's adult ambulatory care clinics between January 1, 2004 and December 31, 2006. Pain intensity information was collected by clinical assistants at each office encounter, chemotherapy infusion and radiation therapy treatment and entered directly into the electronic medical record. The assistants used a standard script to record patients' current pain scores ranging from zero (pain free) to 10 (extreme pain) using a numerical pain intensity scale; infrequently, a visual analogue scale was used if a patient did not understand the numerical scale. Assistants asked each patient to rate their current pain on a scale from zero to 10 in which "zero is no pain and 10 is the worst you can imagine". This scale is widely used and recommended by a variety of organizations for the evaluation of pain intensity (12). For patients who had multiple visits during a single day, the pain scores from the first visit of the day were used. Pain intensity scores were recorded for $96 \%$ of patient visits during this period.

Pain score information electronically abstracted from the medical record was matched with data abstracted from the Dana-Farber Clinical Oncology Research Information System, an electronic database that includes information from the DFCl's tumour registry and registration system. The tumour registry includes cancer International Classification of Disease (ICD) codes, date of diagnosis and disease staging. The registration system includes sociodemographic variables such as age, sex, race, language and insurance type. The Brigham and Women's Hospital (Boston, USA) tumour registry was also used to abstract disease-related information for patients who initially presented at that affiliated hospital.

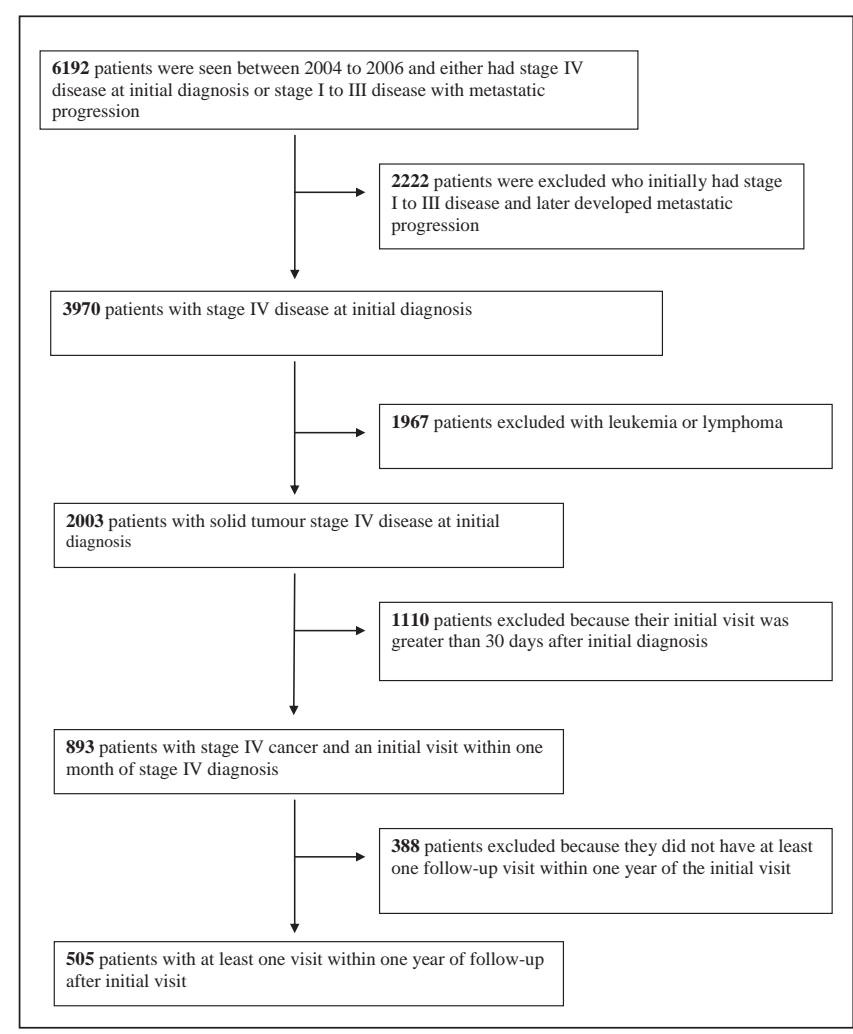

Figure 1) Flow diagram illustrating cohort derivation

Because of their distinct disease course, patients with hematological malignancies were excluded from the cohort. Solid tumour malignancies were classified into the following categories based on ICD-O-3 codes used by the Massachusetts Department of Public Health for their Cancer Incidence and Mortality Report: breast, thoracic, gastrointestinal, urogenital, head and neck and other (Table 1) (13). The tumour registry classifies disease stage according to the American Joint Committee on Cancer Tumour Node Metastasis staging system (14). The diagnosis date in the tumour registry is the date of the cancer diagnosis first reported by the medical practitioner, regardless of whether the diagnosis was histologically confirmed.

\section{Study sample}

Figure 1 illustrates the derivation of the cohort. A total of 6192 solid tumour patients 18 years of age or older were treated at the DFCI between 2004 and 2006, and had stage IV disease at initial diagnosis. Patients who initially had stage I to stage III disease and later developed metastatic progression were excluded because information regarding disease progression from the tumour registry was incomplete; these patients may have also experienced a different pain trajectory compared with patients with advanced disease at diagnosis. Patients with leukemia or lymphoma, patients whose initial visit to the DFCI was greater than 30 days after their initial diagnosis and patients with no follow-up visit within one year of their initial visit were also excluded. The final cohort included 505 patients. Each patient's pain intensity scores during follow-up visits for the year following the initial visit (excluding the pain score reported at their first visit) were examined.

\section{Analyses}

The process of cleaning and matching data required 18 months to complete. Clinical systems often lacked documentation regarding the source and interpretation of various fields. Understanding these data required multiple meetings and repeated data extractions.

Once an analytical data set was prepared, pain scores from each visit were classified into the following categories, according to the National Comprehensive Cancer Network's guidelines for adult pain (12): none (0); mild (1 to 3 ); moderate (4 to 6); and severe (7 to 10 ). 
TABLE 2

Characteristics of newly diagnosed stage IV cancer patients $(n=505)$

\begin{tabular}{|c|c|c|c|c|c|c|c|}
\hline $\begin{array}{l}\text { Patient } \\
\text { characteristic }\end{array}$ & $\begin{array}{c}\text { All cancers } \\
(n=505)\end{array}$ & $\begin{array}{l}\text { Breast } \\
(n=34)\end{array}$ & $\begin{array}{c}\text { Thoracic } \\
(n=190)\end{array}$ & $\begin{array}{c}\text { Gastrointestinal } \\
(n=124)\end{array}$ & $\begin{array}{l}\text { Urogenital } \\
\qquad(n=45)\end{array}$ & $\begin{array}{l}\text { Head and neck } \\
\qquad(n=76)\end{array}$ & $\begin{array}{l}\text { Other* } \\
(n=36)\end{array}$ \\
\hline \multicolumn{8}{|l|}{ Age, years } \\
\hline $18-49$ & $103(20)$ & $15(44)$ & $29(15)$ & $29(23)$ & $8(18)$ & $16(21)$ & $6(17)$ \\
\hline $50-64$ & $237(47)$ & $12(35)$ & $89(47)$ & $61(49)$ & $19(42)$ & 37 (49) & $19(53)$ \\
\hline$\geq 65$ & $165(33)$ & $7(21)$ & $72(38)$ & $34(27)$ & $18(40)$ & $23(30)$ & $11(31)$ \\
\hline \multicolumn{8}{|l|}{ Sex } \\
\hline Female & $266(53)$ & 34 (100) & $99(52)$ & $54(44)$ & $10(22)$ & $11(14)$ & 31 (86) \\
\hline Male & $239(47)$ & $0(0)$ & $91(48)$ & $70(57)$ & $35(78)$ & $65(86)$ & $5(14)$ \\
\hline \multicolumn{8}{|l|}{ Race } \\
\hline White & $458(91)$ & $31(94)$ & $175(93)$ & $111(90)$ & $42(93)$ & $69(92)$ & $30(83)$ \\
\hline Black & $19(4)$ & $0(0)$ & $4(2)$ & $6(5)$ & $2(4)$ & $3(4)$ & 4 (11) \\
\hline Other & $25(5)$ & $2(6)$ & $10(5)$ & $7(6)$ & $1(2)$ & $3(4)$ & $2(6)$ \\
\hline \multicolumn{8}{|l|}{ Primary language } \\
\hline English & 479 (95) & $32(94)$ & $182(96)$ & $116(94)$ & $43(96)$ & $73(96)$ & $33(92)$ \\
\hline Other & $25(4)$ & $2(6)$ & $8(4)$ & $7(6)$ & $2(4)$ & $3(4)$ & $3(8)$ \\
\hline \multicolumn{8}{|l|}{ Insurance } \\
\hline Medicare & $165(33)$ & $7(21)$ & $66(35)$ & $33(27)$ & $19(43)$ & $28(37)$ & 12 (33) \\
\hline Medicaid/free/self-insured & $25(5)$ & $0(0)$ & $9(5)$ & $7(6)$ & $1(2)$ & $4(5)$ & $4(11)$ \\
\hline Private insurance & $312(62)$ & $26(79)$ & $115(61)$ & $83(67)$ & $24(55)$ & $44(58)$ & $20(56)$ \\
\hline \multicolumn{8}{|l|}{ Pain intensity at initial visit } \\
\hline None $(0)$ & $340(67)$ & $24(70)$ & $121(64)$ & $79(64)$ & $39(87)$ & $50(66)$ & $27(75)$ \\
\hline Mild (1-3) & $90(18)$ & $5(15)$ & 35 (18) & $27(22)$ & $4(9)$ & $15(20)$ & $4(11)$ \\
\hline Moderate (4-6) & $48(10)$ & $5(15)$ & $22(12)$ & $11(9)$ & $1(2)$ & $7(9)$ & $2(6)$ \\
\hline Severe $(7-10)$ & $27(5)$ & $0(0)$ & $12(6)$ & $7(6)$ & $1(2)$ & $4(5)$ & $3(8)$ \\
\hline
\end{tabular}

Data presented as $n$ (\%). *'Other' includes central nervous system cancers, melanomas and sarcomas (see Table 1). Percentages are rounded to the nearest integer and may not add to $100 \%$.

The percentage of patients who experienced pain at the initial appointment following the diagnosis of stage IV cancer was calculated. The incidence of severe pain was then examined by identifying the maximum pain score reported during follow-up visits over one year, stratified according to cancer type.

The incidence of severe pain over the year following diagnosis was calculated for patients with mild, moderate or severe pain at their initial visit and compared with patients without pain at their initial visit. The associations among severe pain and age, sex, race, language, insurance and cancer type was examined using the $\chi^{2}$ statistic. Finally, a multivariable logistic regression model was created to examine factors associated with experiencing severe pain within one year. All covariates with $\mathrm{P}<0.20$ in the univariate analyses were modelled.

All statistical analyses were conducted using SAS version 9.2 (SAS Institute Inc, USA). The present study was approved by the Dana-Farber Harvard Cancer Centre's institutional review board.

\section{RESULTS}

Cohort characteristics

Of the 505 newly diagnosed solid tumour cancer patients who presented with stage IV disease and visited the cancer centre within 30 days of diagnosis, $340(67.3 \%)$ experienced no pain at the initial visit, 90 (17.8\%) experienced mild pain, 48 (9.5\%) experienced moderate pain and $27(5.4 \%)$ experienced severe pain. Table 2 summarizes the characteristics of these patients, classified by disease type. The majority of patients were white $(91.2 \%)$, spoke English $(96.9 \%)$ and had private insurance (62.2\%). Of the 505 patients, 197 (39.0\%) died during the study period.

Incidence of pain

One hundred forty-seven patients in the cohort (29.1\%) experienced at least one episode of severe pain within one year of the initial visit (excluding pain reported at the initial visit). The median time to a visit in which the patient reported severe pain was 98 days (interquartile
TABLE 3

Highest pain intensity score reported in newly diagnosed stage IV cancer patients within one year of follow-up (excluding initial visit), by pain intensity at the initial visit

\begin{tabular}{|c|c|c|c|c|c|}
\hline \multirow{2}{*}{$\begin{array}{l}\text { Maximum } \\
\text { pain in one } \\
\text { year }\end{array}$} & \multicolumn{5}{|c|}{ Pain level at initial visit } \\
\hline & $\begin{array}{c}\text { None } \\
(n=340)\end{array}$ & $\begin{array}{c}\text { Mild } \\
(n=90)\end{array}$ & $\begin{array}{c}\text { Moderate } \\
(n=48)\end{array}$ & $\begin{array}{l}\text { Severe } \\
(n=27)\end{array}$ & $\begin{array}{c}\text { All } \\
(n=505)\end{array}$ \\
\hline None (0) & 109 (32.1) & $11(10.2)$ & $5(10.4)$ & 3 (11.1) & $128(25.3)$ \\
\hline Mild (1-3) & 58 (17.1) & $21(23.9)$ & $2(4.2)$ & $2(7.4)$ & 83 (16.4) \\
\hline $\begin{array}{l}\text { Moderate } \\
\qquad(4-6)\end{array}$ & $102(30.0)$ & $25(28.4)$ & $17(35.4)$ & $3(11.1)$ & $147(29.1)$ \\
\hline Severe $(7-10)$ & $71(20.9)$ & $33(37.5)$ & $24(50.0)$ & $19(70.4)$ & $147(29.1)$ \\
\hline
\end{tabular}

Data presented as $n$ (\%). Newly diagnosed stage IV cancer patients had a visit within one month of their stage IV diagnosis and had no pain at that visit (in 2004 or 2005); followed up for one year; minimum of at least two visits with pain intensity scores

range 55 to 167 days). Table 3 summarizes the incidence of pain over one year for all cancer types according to the pain intensity score at the initial visit after diagnosis with stage IV disease. Patients with more intense pain at the initial visit were more likely to report severe pain within one year. Of the patients with severe pain at the initial stage IV visit, $70.4 \%$ reported experiencing severe pain at a follow-up visit within one year.

Figure 2 shows the highest pain intensity scores (excluding the initial visit) within one year according to cancer type. Incident severe pain was most common among patients with head and neck $(52.6 \%)$, gastrointestinal (33.9\%) and thoracic (30.5\%) cancers.

Factors associated with severe incident pain

Table 4 summarizes the characteristics of the patients who reported severe pain during any follow-up visit within one year compared with patients who did not. Patients whose primary language was not English were more likely to experience severe pain $(\mathrm{P}=0.01)$. There was a higher 
TABLE 4

Characteristics of newly diagnosed stage IV cancer patients who experienced severe pain within one year (excluding initial visit)

\begin{tabular}{|c|c|c|c|}
\hline \multirow[b]{2}{*}{ Patient characteristic } & \multicolumn{2}{|c|}{ Pain experienced within one year } & \multirow[b]{2}{*}{$\mathbf{P}$} \\
\hline & $\begin{array}{c}\text { None, mild or } \\
\text { moderate }(n=358)\end{array}$ & Severe $(n=147)$ & \\
\hline Age, years & & & 0.47 \\
\hline $18-49$ & $74(20.7)$ & $29(19.7)$ & \\
\hline $50-64$ & $162(45.3)$ & $75(51.0)$ & \\
\hline$\geq 65$ & $122(34.1)$ & $43(29.2)$ & \\
\hline Sex & & & 0.06 \\
\hline Female & $179(50.0)$ & $60(40.8)$ & \\
\hline Male & $179(50.0)$ & $87(59.2)$ & \\
\hline Race & & & 0.09 \\
\hline White & $331(92.7)$ & $127(87.6)$ & \\
\hline Black & $13(3.6)$ & $6(4.1)$ & \\
\hline Other & $13(3.6)$ & $12(8.3)$ & \\
\hline Language & & & $<0.01$ \\
\hline English & $346(96.9)$ & $133(90.5)$ & \\
\hline Other & $11(3.1)$ & $14(9.2)$ & \\
\hline Insurance & & & 0.43 \\
\hline Medicare & $15(4.2)$ & $10(6.9)$ & \\
\hline Medicaid/free/self-insured & $116(32.6)$ & 49 (33.6) & \\
\hline Private insurance & $225(63.2)$ & $87(59.6)$ & \\
\hline Cancer type & & & $<0.01$ \\
\hline Breast & $30(8.4)$ & $4(2.7)$ & \\
\hline Thoracic & $137(38.3)$ & $53(36.1)$ & \\
\hline Gastrointestinal & $83(23.2)$ & $41(27.9)$ & \\
\hline Urogenital & 40 (11.2) & $5(3.4)$ & \\
\hline Head and neck & $37(10.3)$ & 39 (26.5) & \\
\hline Other* & $31(8.7)$ & $5(3.4)$ & \\
\hline
\end{tabular}

Data presented as $n$ (\%) unless otherwise indicated. *'Other' includes central nervous system cancers, melanomas and sarcomas (see Table 1)

incidence of reporting severe pain within one year in patients with head and neck, gastrointestinal and thoracic cancers compared with other cancer types $(\mathrm{P}<0.01)$. Nonwhite patients $(\mathrm{P}=0.09)$ and men $(\mathrm{P}=0.06)$ were also slightly more likely to experience severe pain. No differences in incident pain according to patient age or insurance were observed.

The multivariable analysis identified similar relationships in regression models that included sex, race, language, cancer type and pain at initial visit (Table 5). Patients whose primary language was not English were more likely to experience severe pain (OR 2.90 [95\% CI 1.08 to 7.80]). Patients with head and neck (OR 10.17 [95\% CI 2.87 to 36.00]) and gastrointestinal (OR 4.05 [95\% CI 1.23 to 13.35$]$ ) cancers were more likely to experience incident severe pain compared with patients with breast cancer. Patients with more severe pain at their initial visit were much more likely to experience severe pain during follow-up visits over the next year. For example, patients with severe pain at baseline were 9.3-fold more likely to report experiencing severe pain at a follow-up visit (95\% CI 3.72 to 23.23 ) compared with patients without pain at baseline. A sensitivity analysis in which death within one year was included as a covariate was performed. Patients who died within the year had higher odds of experiencing severe pain (OR 2.14 [95\% CI 1.32 to 3.46]).

\section{DISCUSSION}

Using pain intensity scores recorded at routine office visits, we found that $29.1 \%$ of newly diagnosed stage IV ambulatory oncology patients experienced severe pain within one year of their first visit. Patients with head and neck cancers, gastrointestinal cancers and thoracic cancers had the highest rate of experiencing severe pain. Non-English speakers
TABLE 5

Multivariable logistic regression model of predictors of experiencing severe pain within one year of stage IV cancer diagnosis (excluding initial visit)

\begin{tabular}{lcc}
\hline Patient characteristic & OR & 95\% Cl \\
\hline Sex & & \\
Male & Reference & $0.78-1.84$ \\
Female & 1.15 & \\
Race & & \\
White & Reference & $0.30-2.92$ \\
Black & 0.94 & $0.45-3.28$ \\
Other & 1.21 & \\
Language & & \\
English & Reference & $1.08-7.80$ \\
Other & 2.90 & \\
Cancer type & & \\
Breast & Reference & $0.94-9.63$ \\
Thoracic & 3.00 & $1.23-13.35$ \\
Gastrointestinal & 4.05 & $0.27-5.79$ \\
Urogenital & 1.26 & $2.87-36.00$ \\
Head and neck & 10.17 & $0.26-5.04$ \\
Other* & 1.13 & \\
Pain at initial visit & & $1.23-3.55$ \\
None & Reference & \\
Mild & 2.09 & \\
Moderate & 3.75 & \\
Severe & 9.30 & \\
\hline
\end{tabular}

*'Other' includes central nervous system cancers, melanomas and sarcomas (see Table 1)

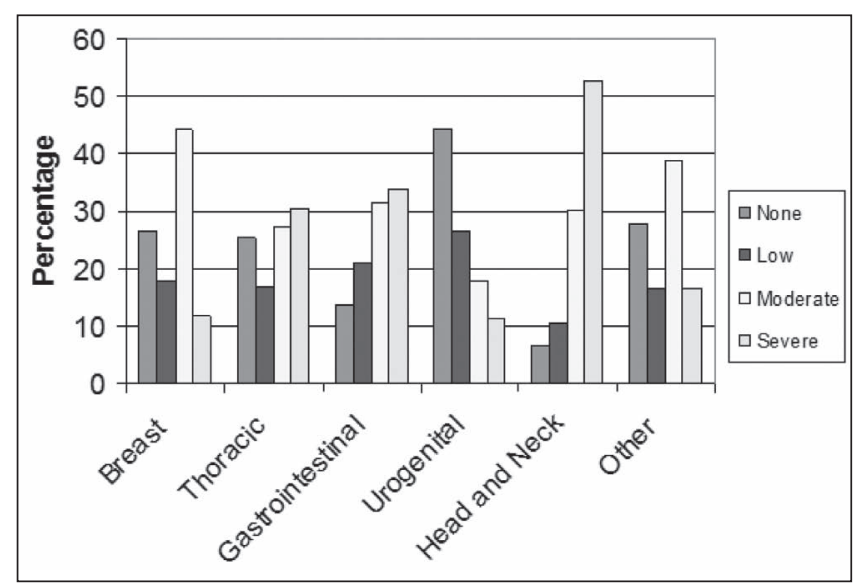

Figure 2) Highest pain intensity score within one year of follow-up among newly diagnosed stage IV cancer patients, according to cancer type $(n=505)$, excluding pain reported at first visit. 'Other' includes central nervous system cancers, melanomas and sarcomas (see Table 1)

were also at greater risk. Patients with severe pain at their initial visit had a nine-fold higher likelihood of reporting severe pain compared with patients without pain at baseline.

The results of the present study are consistent with research regarding the extent of severe pain among patients with advanced cancer. Several studies reported the prevalence of pain among cancer patients to be $30 \%$ to $60 \%$, although frequencies as low as $14 \%$ and as high as $100 \%$ have also been reported (3-7). Prospective longitudinal studies of pain intensity have increasingly focused on breakthrough pain $(8-10)$. The present study attempted to fill a gap in the literature by examining the incidence of pain among patients with various types of stage IV cancer in the ambulatory setting. Existing clinical information captured in the patient's medical record was used to address a question 
that patients may ask their doctors: "What is the chance that I will experience severe pain in the next year?'

There was a high incidence of severe pain in the first year following the initial visit across most cancer types. This was especially striking among patients with head and neck cancers. Previous studies have reported that patients with head and neck malignancies are at high risk for severe and persistent pain. In a prospective study of 93 patients with newly diagnosed head and neck cancer, one-quarter of the patients experienced pain at two years after diagnosis. Patients who reported pain at the three- and 12 -month intervals were likely to experience persistent pain for up to two years (15). Persistent pain was common among patients with both early and advanced-stage disease. The high risk of pain among patients with head and neck cancers is likely multifactorial and attributable, in part, to the anatomical location of the disease, the use of aggressive multimodal therapy, toxicities that affect functions such as speech and swallowing, medical and psychological comorbidities, and patients' social circumstances. Although previous studies have reported variability in the types of cancer that are associated with severe pain, head and neck patients represent a special needs group $(3,16-19)$.

Primary language was found to be associated with severe pain, but there was no association with race. Previous research has reported that racial minorities with cancer tend to report higher levels of pain and to receive inadequate treatment for their pain, although studies do not consistently separate the effects of race and language (20-23). We suspect that communication barriers among non-English speakers increased the risk of undertreatment in our cohort, but discerning whether the barriers for minorities are caused by language or other factors related to race, including education, religion or pain tolerance, requires further study (24-26).

The results of the present study may inform clinical oncology practice by providing information to clinicians and patients regarding what to expect after a new diagnosis of stage IV cancer. Clinicians may use this information to counsel their patients in advance of their treatment, and to identify patients for intensive pain surveillance and early intervention. In addition, the present study demonstrates the potential utility of routinely collected clinical information as a

\section{REFERENCES}

1. Goudas LC, Bloch R, Gialeli-Goudas M, et al. The epidemiology of cancer pain. Cancer Invest 2005;23:182-90.

2. Mantyh PW. Cancer pain and its impact on diagnosis, survival and quality of life. Nat Rev Neurosci 2006;7:797-809.

3. van den Beuken-van Everdingen MHJ, de Rijke JM, Kessles AG, Schouten HC, van Kleef M, Patijn J. Prevalence of pain in patients with cancer: A systematic review of the past 40 years. Ann Oncol 2007; 18:1437-49.

4. Wilson KG, Chochinov HM, Allard P, et al. Prevalence and correlates of pain in the Canadian National Palliative Care Survey. Pain Res Manag 2009;14:365-70.

5. Breivik H, Cherny N, Collett B, et al. Cancer-related pain: A pan-European survey of prevalence, treatment, and patient attitudes. Ann Oncol 2009;20:1420-33.

6. van den Beuken-van Everdingen MH, de Rijke JM, Kessels AG, Schouten HC, van Kleef M, Patijn J. High prevalence of pain in patients with cancer in a large population-based study in the Netherlands. Pain 2007;132:312-20.

7. Coyle N, Adelhardt J, Foley KM, et al. Character of terminal illness in the advanced cancer patient: Pain and other symptoms during the last four weeks of life. J Pain Symptom Manage 1990;5:83-93.

8. Meuser T, Pietruck C, Radbruch L, et al. Symptoms during cancer pain treatment following WHO-guidelines: A longitudinal follow-up study of symptom prevalence, severity and etiology. Pain 2001;93:247-57.

9. Green CR, Mantague L, Hart-Johnson TA. Consistent and breakthrough pain in diverse advanced cancer patients: Longitudinal examination. J Pain Symptom Manage 2009;37:831-47.

10. Greco MT, Corli O, Montanari M, et al. Epidemiology and pattern of care of breakthrough cancer pain in a longitudinal sample of cancer patients: Results from the Cancer Pain Outcome Research Group. Clin J Pain 2011;27:9-18. resource for research in this area, to inform the development of decision tools for patients and providers, and to identify targets for quality improvement.

There were several limitations to the present study. First, we examined cancer patients treated at a single cancer centre. Treatment patterns and patient factors may differ at other institutions. Second, we were unable to examine concurrent chemotherapy or radiation treatment, or pain medication management. Examining the impact of concurrent disease and treatment factors will be a focus of our future research. Third, we examined only patients with newly diagnosed stage IV cancer; these results should not be extrapolated to patients who progress to metastatic disease. Additional studies are required to understand pain and its care at the end of life. Finally, the present study relied on routinely collected information to ascertain pain intensity. While the use of clinical data limits the types of research questions that one might pursue, it offers a mechanism for examining the epidemiology of pain in busy clinical practice settings. Accessing and analyzing this information posed an operational challenge that prolonged the present project. However, our understanding of these data now offers opportunities to use the electronic medical record more efficiently for research and improvement.

In summary, severe pain is common among patients who present with advanced-stage cancer, particularly for non-English speakers, patients with severe pain at their first visit, and patients with head and neck, thoracic or gastrointestinal cancers. Providers should educate patients regarding the possibility of experiencing severe pain and monitor high-risk patients closely.

SUPPORT AND DISCLOSURES: The present research was supported by an American Cancer Society Pilot and Exploratory Project Grant (PEP-08-273-01-PC1) and performed at Dana-Farber Cancer Institute. The funding organization had no role in the design and conduct of the study, in the collection, management, analysis and interpretation of the data, or in the preparation, review or approval of the manuscript. The authors have no disclosures or conflicts of interest to report with regard to this work.

11. Patrick DL, Ferketich SL, Frame PS, et al. National Institutes of Health State-of-the-Science Conference Statement. Symptom management in cancer: Pain, depression, and fatigue, July 15-17, 2002. J Natl Cancer Inst 2003;95:1110-17.

12. National Comprehensive Cancer Network. Cancer Pain. Practice Guidelines in Oncology, v.1.2004. National Comprehensive Cancer Network: Fort Washington, 2004.

13. Cancer Incidence and Mortality in Massachusetts, 2002-2006. Statewide Report. Commonwealth of Massachusetts, Department of Public Health, Bureau of Health Statistics, Research and Evaluation, Massachusetts Cancer Registry; June 2009.

14. Data Collection Manual Massachusetts Cancer Registry Abstracting and Coding Manual for Hospitals. Commonwealth of Massachusetts. Bureau of Health Information, Statistics, Research and Evaluation; December 2003.

15. Chaplin JM, Morton RP. A prospective, longitudinal study of pain in head and neck cancer patients. Head Neck 1999;21:531-7.

16. Williams JE, Yen JT, Parker G, et al. Prevalence of pain in head and neck cancer out-patients. J Laryngol Otol 2010;124:767-73.

17. Trotti A, Bellm LA, Epstein JB, et al. Mucositis incidence, severity and associated outcomes in patients with head and neck cancer receiving radiotherapy with or without chemotherapy: A systematic literature review. Radiother Oncol 2003;66:253-62.

18. van Wilgen CP, Dijkstra PU, van der Laan BF, et al. Morbidity of the neck after head and neck cancer therapy. Head Neck 2004;26:785-91.

19. Bhatnagar S, Upadhyay S, Mishra S. Prevalence and characteristics of breakthrough pain in patients with head and neck cancer: A cross-sectional study. J Palliat Med 2010;13:291-5.

20. Cleeland CS, Gonin R, Hatfield AK, et al. Pain and its treatment in outpatients with metastatic cancer. N Engl J Med 1994;330:592-6. 
21. Vallerand AH, Hasenau S, Templin T, et al. Disparities between black and white patients with cancer pain: The effect of perception of control over pain. Pain Med 2005;6:242-50.

22. Rabow MW, Dibble SL. Ethnic differences in pain among outpatients with terminal and end-stage chronic illness. Pain Med 2005;6:235-41.

23. Cleeland CS, Gonin R, Baez L, et al. Pain and treatment of pain in minority patients with cancer. The Eastern Cooperative Oncology Group Minority Outpatient Pain Study. Ann Intern Med 1997;127:813-6.
24. Bernabei R, Gambassi G, Lapane K, et al. Management of pain in elderly patients with cancer. SAGE Study Group. Systematic Assessment of Geriatric Drug Use via Epidemiology. JAMA 1998;279:1877-82.

25. Brescia FJ, Portenoy RK, Ryan M, et al. Pain, opioid use, and survival in hospitalized patients with advanced cancer. J Clin Oncol 1992;10:149-55.

26. Rustoen T, Fossa SD, Skarstein J, et al. The impact of demographic and disease-specific variables on pain in cancer patients. J Pain Symptom Manage 2003;26:696-704. 


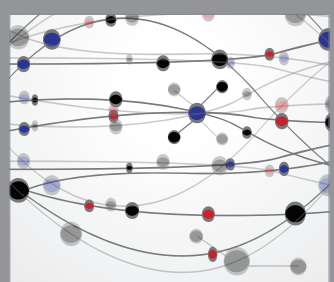

The Scientific World Journal
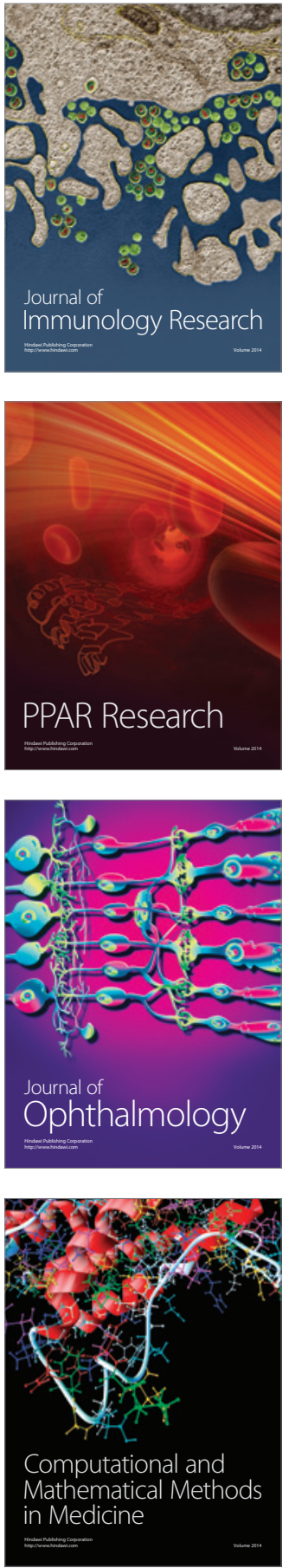

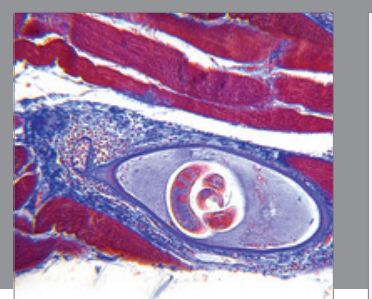

Gastroenterology Research and Practice

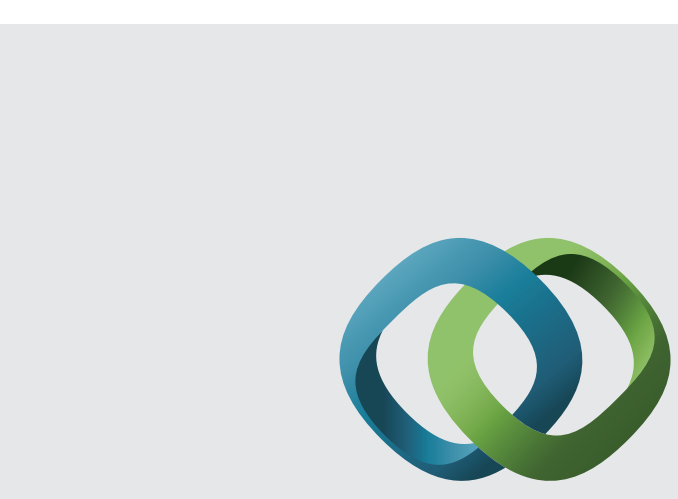

\section{Hindawi}

Submit your manuscripts at

http://www.hindawi.com
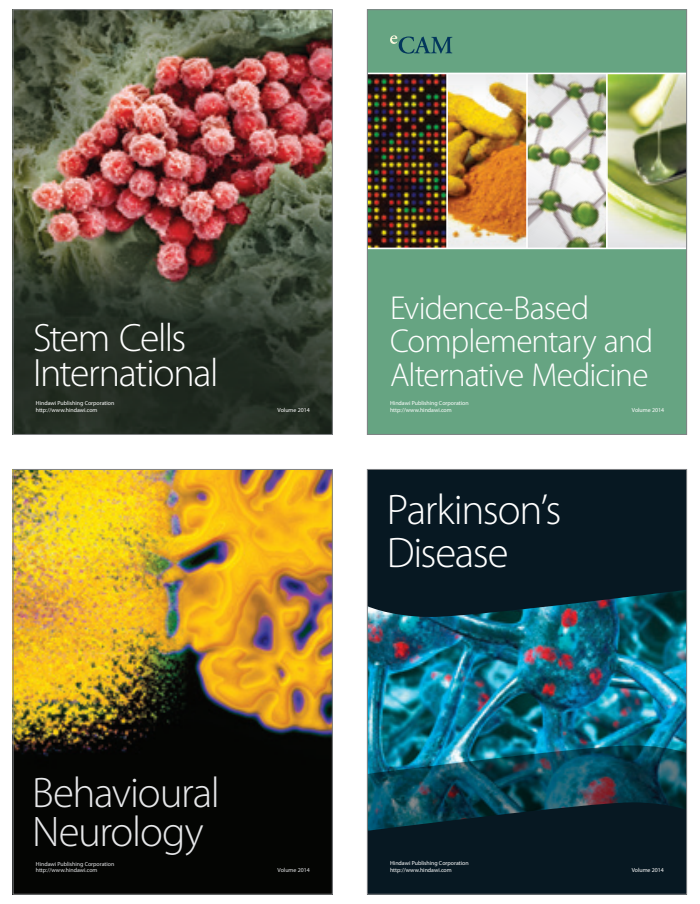
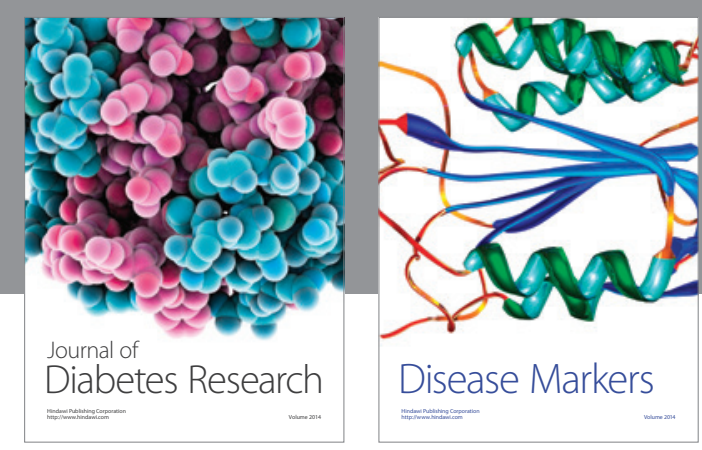

Disease Markers
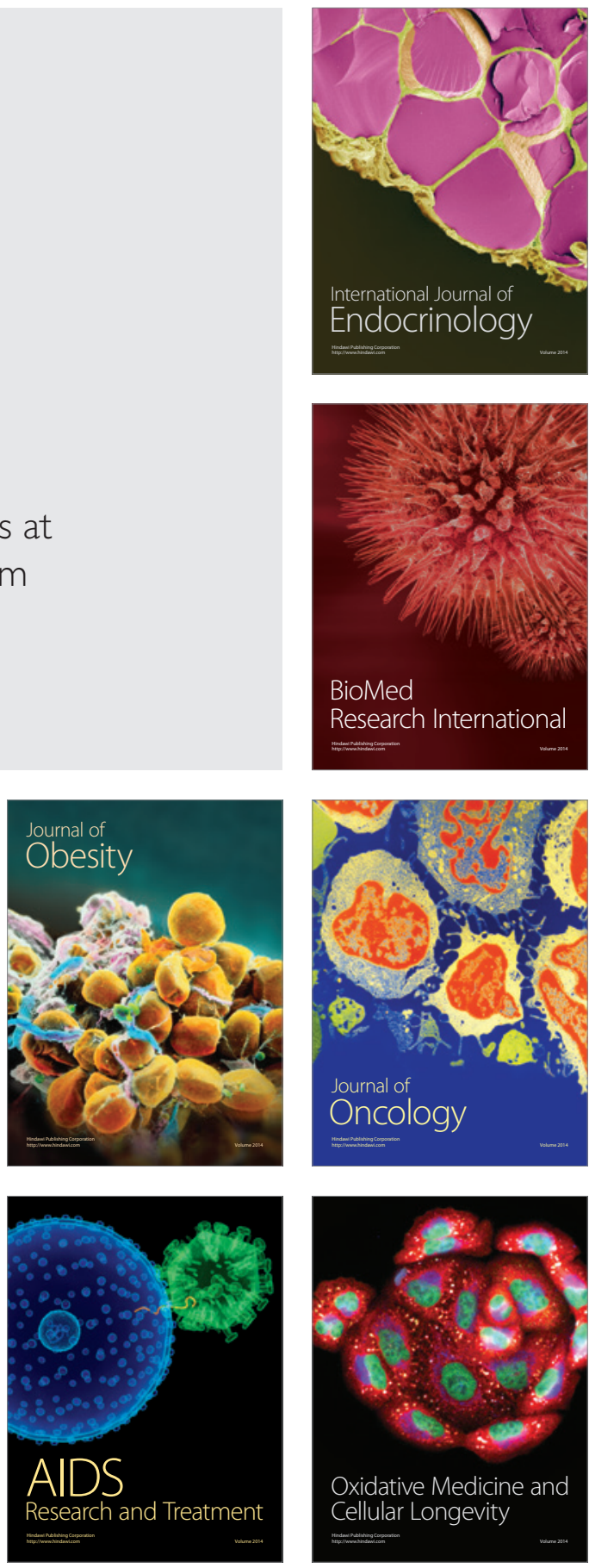